Royal Colleges of Surgeons and Physicians in London. To obtain these diplomas, candidates before presenting themselves for examination, have to attend certain prescribed courses of instruction on anatomy and physiology of the eye, physiological optics and pathology. The result has been the establishment at the University of Oxford, and at the different Ophthalmic Hospitals in London of special courses to meet these requirements.

This brief outline of the growth of ophthalmic teaching in this country will serve to show that it has developed, not as the result of any set plan, but by gradual accretions to meet the requirements of students and the advances of knowledge.

The committee of the American Ophthalmological Society in the concluding passages in its report states :

"It is certainly surprising that no one has ever offered to donate a large sum for the advancement of ophthalmology. This must be due to the fact that our needs have not been sufficiently advertised."

It is probably still more surprising that the teaching at Moorfields has been so successfully carried on for over one hundred years without any endowment, the only funds available being those derived from the students' fees. How much this redounds to the self-sacrificing services of the members of the surgical staff, past and present, may be gathered from the next paragraph of the report which runs as follows :

"The chief difficulty in organizing a graduate school of ophthalmology is in obtaining properly qualified teachers who are willing to devote sufficient time to the school. Most ophthalmologists feel that after they have given a large part of their time to clinical work in the hospital they must devote the rest of their time to making a living in private practice. The only way this difficulty can be overcome is to provide adequate salaries for the teachers."

\title{
ABSTRACTS
}

\section{I.-DISEASES OF RETINA}

(I) Sourdille, G. (Nantes).-A method of treating detachment of the retina. (Une méthode de traitement de décollement de la rétine.) Arch. d'Ophtal., July, 1923.

(1) In this paper, presented to l'Académie de Médecine, Prof. Sourdille recounts his experiences, and describes the technique he employs in the treatment of detachment of the retina by operative measures. He is much more sanguine than most writers on this subject and certainly his published results seem to justify his optimism. He deplores the fact that repeated failures have so 
discouraged many surgeons that they have desisted from further attempts; " at the present time scepticism is almost universal, and more than ever before detachment of the retina, both to the laity and the medical profession, maintains its unenviable reputation of incurability."

Before describing his views and methods, the author refers briefly to the work of numerous observers, such as $\mathrm{H}$. Müller, de Wecker, Leber, Nordenson and others, and their opinions on the pathogenesis of detachment. His own anatomical and clinical researches have led him to opinions which he thinks agree better than earlier hypotheses with observed facts, but these he reserves for a later communication.

Any form of treatment should be guided by two principles: (1) to favour the re-adaptation of the retina to its pigment epithelium ; (2) to induce in the choroid and the epithelium an inflammatory reaction sufficient to bring about adhesion of these two structures without exciting anatomical changes which might impair vision.

The obstacles to the replacement of the retina in contact with the pigment epithelium are, in recent cases, $(a)$ the presence of subretinal fluid, (b) retraction of the detached retina. Although the retina itself contains no elastic or contractile elements the author believes that the blood-vessels of the detached retina exert a contractile influence, and tend to assume and to cause the retina to assume, the direction of the chord of the arc which they followed when the retina was in situ. In detachment of long standing there are also other obstacles due to degenerative changes in the vitreous and the retina. If these are in an advanced stage the detachment has become incurable. To ensure the replacement of the retina the two obstacles $(a)$ and $(b)$ must be overcome; to attain this result two procedures are essential and are sometimes sufficient ; they are evacuation of the subretinal fluid by multiple punctures of the sclera and choroid and perforation of the retina.

Sourdille has two methods of operating which he describes in detail and illustrates by diagrams. A very condensed report of these must suffice; those who are interested will do well to read his description. In the first method, which he employs in nearly all cases, he uses a narrow, sharp-pointed thin Graefe knife. With this he makes three or four punctures, entering the knife at least 10 or $12 \mathrm{~mm}$. towards the centre of the eyeball, traversing the subretinal space and perforating the detached retina. By slight rotation of the blade vitreous is allowed to escape beneath the conjunctiva, and the knife is then withdrawn. Into the oedematous subconjunctival area which results, 1 to $2 \mathrm{c.cm}$. of aqueous solution of cyanide of mercury, $1-1,000$, to which a few drops of 5 per cent. solution of cocain or novocain have been added, are injected. This fluid, the author thinks, finds its way through the scleral punctures. The eye is then bandaged and the patient kept at rest on his back. 
In three instances a fine galvano-cautery point was used instead of the knife. This method the author reserves for shallow detachments.

As soon as the chemosis and injection following the operation have subsided, subconjunctival injections of 6 per cent. solution of $\mathrm{Na} \mathrm{Cl}$ are given once a week. Complete rest is enforced for about three weeks.

In a period of $2 \frac{1}{2}$ years, Sourdille has operated upon 35 eyes in 30 patients; one case being still under treatment is not included in his results. In 16 cases of recent detachment he claims nine permanent cures and one lasting improvement. In 18 cases of detachment of long standing he had nine with permanent improvement.

Clinical notes of 12 cases are appended. Sourdille's results in the treatment of one of the most intractable of ocular diseases are so striking that the methods he advocates deserve attention. The principle of tapping the subretinal space through the sclera and choroid, and the vitreous chamber through the detached retina can scarcely be considered novel and the method in which the galvanocautery is employed, is already familiar, at least to surgeons in this country. In several respects, however, the author has departed from former practice and the results obtained by him should encourage further attempts on somewhat similar lines.

\section{J. B. LAWFORD.}

(2) Greenwood, Allen (Boston). - Thrombosis of the central retinal vein and its branches. Jl. of the Amer. Med. Assoc., January, 1924.

(2) Greenwood, in discussing this subject and reviewing the literature, believes that the venous obstruction is always slow in developing and that when one of the retinal branches is involved the first compression of the vein has been due to an overlying, thickened artery or a thickened artery which winds round the vein. When the central artery is involved the obstruction occurs at the lamina cribrosa and here the central vein is compressed by a thickened artery ; probably an endophlebitis is present at the point where the vein is pressed upon, with the final formation of a thrombus.

He points out that the treatment must be directed to the restoration of vision as far as possible and the prevention of glaucoma. $\mathrm{He}$ uses amyl nitrite inhalations and some form of nitrite internally, pilocarpin and purges. Iodine preparations internally are useful for prolonged treatment, small doses of syrup of hydriodic acid can be similarly used. It is important to take the tension frequently, and miotics should be prescribed even when there is no increased tension. It is important to have the patient generally overhauled.

\section{E. R. Chambers.}




\section{II.-OPTIC NERVE}

(I) Archer-Hall, H. W. (Birmingham). -A case of bilateral retro-ocular neuritis. Lancet, April 1, 1922.

(1) Archer-Hall's case is an interesting one from the aetiological standpoint. A married woman aged 22, suffered from double retro-ocular neuritis. A dental septic focus was suspected and the teeth were radiographed by Dr. Harold Black. The patient and the radiograms were taken to $\mathrm{Mr}$. Harold Round, who, on casual examination, did not think there was much chance of finding anything orally to account for the condition. Yet, on more careful examination, along with the radiograms, three teeth were suspected and removed. Two out of three showed apical absorption. The patient recovered full vision and fields at the end of five or six weeks, although originally she had been so blind that she had had to be led. Assuming the correctness of the relation between cause and effect in this case, what strikes one is the difficulty of diagnosis of a septic dental focus giving very slight symptoms or signs and yet sufficient to cause severe retro-ocular neuritis. Prints of ten radiograms accompany the article.

ERNEST ThOMSON.

(2) Martin, Paul, and Cushing, Harvey.-Primary gliomas of the chiasm and optic nerves in their intracranial portion. Arch. of Ophthal., Vol. LII, No. 3, p. 209, May, 1923.

(2) This valuable and suggestive paper by Martin and Cushing deals with the records of seven tumours (gliomatous) originating either in the chiasm or in the optic nerves adjacent to it. It is profusely and beautifully illustrated. One of its main objects is to suggest to ophthalmologists an explanation of some of those obscure cases of primary optic atrophy which they so often vaguely attribute to retro- . bulbar neuritis. The association of a primary atrophy of the optic nerves in young people with the peculiar sellar deformation which is described in this paper, in the absence of the shadows usually cast by the more common tumours of this region in childhood, will suggest the possibility that the symptoms are due to a primary glioma of the chiasm, and will prevent the undertaking of useless operative procedures in this hopeless class of cases.

R. H. Elliot.

(3) Brazeau, G. N. (Milwaukee, Wis.).-Serous tenonitis complicated by bilateral papilloedema. Arch. of Ophthal., July, 1923.

(3) Brazeau's case occurred in a healthy man aged 30. There was bilateral proptosis, complete external ophthalmoplegia, marked 
chemosis in the left eye, and bilateral papilloedema, the swelling in the right eye being $1 \mathrm{D}$, and in the left $4 \mathrm{D}$. Visual acuity was normal. There was nothing to indicate cerebral tumour; orbital cellulitis was ruled out by the absence of pain and tenderness on pressure and by negative $\mathrm{X}$-ray findings.

The case was regarded as one of tenonitis of rheumatic origin. Treatment consisted of 'sodii sal. grs. 10, aspirin grs. 5, thrice daily. This was successful within six weeks, when all manifestations disappeared except a paralysis of the left inferior oblique muscle.

F. A. Williamson-Noble.

(4) Woods, Alan C., and Dunn, J. R.-Etiologic study of a series of optic neuropathies. Jl. Amer. Med. Assoc., April 21, 1923.

(4) Woods and Dunn in this paper give their experience in a series of eighty-six patients who presented various optic nerve changes, and try to determine the possible relationship of any of these changes to nasal sinus disease.

Cases of trauma, glaucoma, retinitis pigmentosa, and cases referred from other departments for consultation are excluded from the series, which includes only those cases which presented themselves at the clinic on account of visual disturbances. The examination was undertaken in the following order: a complete ophthalmological examination, medical, neurological, laryngological, and serological examinations.

Thirty-five optic neuropathies, or 40 per cent. of the total cases studied were due to syphilis ; 11 , or 12.7 per cent. were caused by sinus disease; 10 , or 11.6 per cent. were due to tumours of the cerebrum or optic nerve; five, or 5.8 per cent were due to multiple sclerosis; ten, or 11.6 per cent. belonged to the toxic amblyopia group; three, or 3.5 per cent. occurred in widely separated conditions, Friedreich's disease group, Mongolian idiocy, and -epidemic encephalitis lethargica. In 12 cases, or 14 per cent., no definite diagnosis was justifiable.

From the ophthalmological point of view, there were 35 cases of primary atrophy; of these, 25 were due to syphilis, one to multiple sclerosis, four to the toxic amblyopia group, and five were undetermined. There were 13 cases of secondary atrophy, of which two were due to syphilis, four to brain tumour, one occurred in Mongolian idiocy, and four were undetermined. There were 24 cases of atrophy of the papillo-macular bundle; of these, four apparently due to syphilis, six to sinus disease, one to brain tumour, four to multiple sclerosis, five to toxic amblyopia, one to the Friedreich's disease group, and three were undetermined. There were five cases of optic neuritis; three of these occurred in syphilis, one in the taxic amblyopia group, and one in epidemic 
encephalitis. Four cases of choked disc were seen, and in all a tumour of the brain was located ; five cases of retro-bulbar neuritis complete the series; one of these was due to syphilis, four to sinus disease, and in one case there was a pre-chiasmal tumour of the optic nerve.

As regards the sinus disease cases, four were in the acute stage and seven in the atrophic stage. The acute cases all presented the same clinical picture, that of a retro-bulbar neuritis, with clear media, diminished vision, normal fundi and a central scotoma; three of these patients had a pyogenic infection of the ethmoidal sinuses, and two of them showed a complicating infection of the sphenoidal sinus; the fourth case !had nothing but polypi in the posterior ethmoidal cells. All four cases were operated on and made a complete recovery.

Five of the patients in the atrophic stage gave the picture of a primary atrophy of the papillo-macular bundle, without any signs of previous inflammation round the nerve head; one case showed a general atrophy especially marked in the outer half of the disc, with blurring of the margins and a deposit of new connective tissue in the physiological cup; the last patient of this series showed a secondary atrophy of the optic nerve. This case had evidence of old ethmoidal infection, and there was a history of a previous positive Wassermann reaction, but two Wassermann reactions performed in the Johns Hopkins Hospital were negative, and the case was therefore included in the nasal sinus group and not in the syphilitic. The authors enter a plea for a more standard nomenclature in dealing with the optic inflammations and atrophies, advocating the employment of the term optic neuritis for cases where actual inflammation of the nerve head is present and reserving the term choked dise for cases where increased intra-cranial pressure is the cause of the fundus manifestation. If it be impossible to determine which cause is at work, then the term papilloedema meets the case ; they would like to abolish the terms axial, ascending and descending neuritis, in order to clarify the terminology.

\section{R.R.J.}

(5) Caldeira.-Primary tumours (intradural) of the optic nerve. (Tumores primitivos intradurales do nervo optico.) Faculdade de Medicina e Chirurgia de Sao Paulo. 51 pp. with 8 plates. Sao Paulo, 1923.

(5) This little brochure is Caldeira's thesis presented and defended at the Medical and Surgical Faculty of Sao Paulo in March, 1923. The foundation of it is four cases observed since 1918, but the first 32 pages deal with the history, aetiology, pathological anatomy, symptomatology, topographical classification, prognosis 
and treatment of the condition. In the historical section we were pleased to see a reference to Hudson's paper published in 1912 .

The author's first case was in a boy, aged 7 years with very marked protrusion of the eye in a downward and outward direction; the proptosed eye was quite irreducible, there was no pulsation, and the eye was blind, the fundus examination showing a condition of post-neuritic atrophy. The eye and tumour were removed together, the tumour being found to extend right up to the apex of the orbit. The report was: a malignant soft glioma of the sheath, which had invaded the nerve proper, leading to atrophy of the same.

The second case occurred in a female patient, aged 39 years, with a long history of slowly increasing exophthalmos; the protrusion was not so marked as in the first case ; the eye was blind and the fundus examination showed a temporal atrophy of the nerve head. The mass was removed with preservation of the globe according to the method of Lagrange, and the report was: glioma of the optic nerve.

The third case was in a female, aged 24 years. The eye was preserved in removing the tumour, and the diagnosis was : fibroglioma of the optic nerve with central cyst of degeneration.

The fourth case appears from the photograph to have occurred in a little girl. The tumour was removed with preservation of the globe, but details in the text seem to be wanting.

(6) Vinsonneau, C. (Antwerp).--Retrobulbar optic neuritis and sphenoidal sinusitis. (Névrite optique rétro-bulbaire et sinusite sphénoïdale.) Arch. d'Ophtal., February, 1924.

(6) Vinsonneau, in discussing the question of sphenoidal sinusitis in connection with retrobulbar neuritis, gives no new facts of his own, and although he mentions several authorities gives no bibliography or references. He comes to the following conclusions: "(1) The pathological relationship of the antrum, sphenoidal sinus and nasal sinuses with the pathological state of the optic nerve is of daily observation and lends support to the conception: the sphenoidal sinus is frequently of aetiological importance in cases of acute retrobulbar neuritis. Nevertheless such frequency should not be considered an absolute rule if the clinical evolution of certain cases is duly followed up. There exist then two well defined pathological chapters : (a) functional disturbances of the optic nerve, and subacute and latent infection of the nasal fossae, sphenoidal sinus and antrum ; $(b)$ retrobulbar neuritis and sphenoidal sinusitis. (2) From the therapeutic point of view it is necessary to differentiate the sphenoiditis with retention but without infection from the severe sphenoiditis with retention and infection; the procedure to be followed is absolutely difterent in the two cases. It is to be 
remembered that the success of intervention in the sphenoidal sinus is not a simple question of operative technique and that a relapse as a result of contraction of the opening frequently occurs. (3). The attention of the ophthalmologist should be drawn more and more to the research of an aetiology of nasal or naso-pharyngeal origin for the explanation of numerous cases in ocular pathology. From which we may conclude that, in what concerns the education of our students, we should insist more and more on the relations, both physiological and anatomical, between the orbit and its contents on the one hand, and the nasal fossae, antrum and adjoining sinuses on the other. Such bilateral education will bear fruit, provided that, at the same time, prudence in rhinological therapeutic diagnosis is taught to these future practitioners."

E.E.H.

(7) Velter and Liebault-Acute retro-bulbar neuritis : polypus of the sphenoidal sinus: removal: cure. (Névrite rétrobulbaire aiguë: polype du sinus sphénoïdal : ablation : guérison.) Arch.d'Ophtal., March, 1923.

(7) Velter and Liebault report the case of a woman, aged 27, in whom an acute retro-bulbar optic neuritis (right-sided) with characteristic signs and symptoms, developed twelve days before she came under observation. Vision was almost abolished, "less than 1 per cent." A polypus "the size of a green pea "was removed from the right sphenoidal sinus on December 24. Improvement in the ocular condition began within three days, and by February 6, vision had recovered to $8 / 10$, though a small relative central scotoma persisted.

J. B. LAWFORD.

\section{III.-MISCELLANEOUS}

(I) Contino, Prof. A. (Sassari).-Histogenesis of molluscum contagiosum of the lids. (Istogenesidel mollusco contagioso delle palpebre.) Annal. di Ottal. e Clin. Ocul., June-JulyAugust, 1923.

(1) Contino refers to the theory advanced by Virchow, and supported by many famous pathologists, of the origin of molluscum contagiosum in the sebaceous glands of hair follicles, and to the opposed theory of its origin from cutaneous epithelium. As refuting the sebaceous gland theory, he quotes the unique case 
described by Ballaban, of molluscum on the bulbar conjunctiva, where there are no sebaceous glands.

For several years the author, whenever he has come across multiple small mollusca of the lids, has excised them, stained them in bulk, and cut serial sections. He has also made a considerable number of wax models from the sections. As a result of his observations he states that molluscum contagiosum consists essentially in a hyperplasia of the cutaneous epithelium, due to a specific agent which stimulates the proliferation of the germinal layer of the epithelium, and also produces changes in the newly-formed cells, which, together with their physiological tendency to keratinization, are the cause of the formation of the molluscum bodies.

Keratinization of the epithelial cells is an indispensable factor in the formation of molluscum bodies, and, therefore, molluscum contagiosum can only occur where there is epithelium which normally undergoes keratinization, namely skin epithelium, including that invaginated to form the openings of hair follicles and sweat glands. Ballaban's case, mentioned above, he attributes to the existence of a congenital island of skin epithelium on the bulbar conjunctiva. In more than a third of the cases examined, the opening of the molluscum was in common with that of a hair follicle. This he explains by suggesting that the opening of the hair follicle affords a ready nidus for the virus. As the molluscum grows the hair follicle is displaced, and atrophies, and in large mollusca a small column of epithelial cells, protruding from the epithelial mantle which surrounds the aperture, represents the last remnant of a hair follicle, and can be recognized by the difference of its cells from those of the molluscum.

In his researches he finds that the first histological alteration in the epithelium, which indicates that a molluscum is about to form, is a circumscribed proliferation of the cells of the germinal layer, becoming a bud or a column which becomes buried in the derma. The newly-formed epithelial bud is distinguished from the surrounding inter-papillary epithelial columns not so much by its shape as by its peculiar structure and the changes which, even in the earliest stages, occur in its constituent cells, and by a more or less marked small-cell infiltration of the surrounding derma.

The author publishes eighteen micro-photographs, the first of which shows a very early, and so far undescribed, stage of molluscum. It is a globular mass of cells measuring $80 \mu \times 90 \mu$, buried in the apex of a dermal papilla. The basal layer of the epithelium, when it passes on to the molluscum bud, changes in character, the cells having more cytoplasm, and an obvious nucleus with evident chromoplasm. The change is more evident at the superficial part of the bud, giving the impression that the bud arises from the layer of cells immediately above the basal 
layer. Within the bud, in contact with the germinal layer, there are large vesicular cells, some of which have a deeply staining globule alongside the nucleus. This is the first stage in the formation of a molluscum body. In the middle of the mass there are two small rounded cavities, the larger of which contains two wrinkled cells, which show better the characteristic corpuscle. The skin papilla, in which the mass is embedded, shows a slight inflammatory infiltration. The author remarks that this description shows the molluscum body to be a very early manifestation in the development of molluscum contagiosum. Other preparations of later stages show swollen cells, which become shrunken, not only the cell body, but also the nucleus, becoming wrinkled. As the cells shrink, one or more deeply staining bodies appear alongside the nucleus. These cells show fine granules of kerato-hyalin. The author emphasizes the inflammatory reaction in the surrounding tissues, which he regards as a defence against the specific toxin rather than due to mechanical irritation by the tumour. He describes in minute detail other preparations showing every stage up to the fully formed molluscum. He concludes that there are three stages in the cell changes : first, swelling and hydrolysis of the endoplasm; second, gelatinization of the endoplasm, giving the appearance of molluscum bodies; and third, their complete keratinization. He finds no evidence of micro-organisms. He gives a bibliography.

A. D. Griffith.

(2) Bettin, Mona E. (Los Angeles.)-Report of a case of torula
infection. California and Western Medicine, March, 1924.

(2) The torula is a wild yeast, it does not form spores nor does it ferment sugars. It does not produce mycelium either in cultures or in the tissues. It appears to have a predilection for the central nervous system and does not give rise to a general infection. Cases of torula infection in human beings were reported by Stoddard and Cutler in 1916 from the Rockfeller Institute. They had two cases and found records of four others in the literature. A case was reported by Pierson of San Francisco in 1917, and Evans of Loma Linda reported two in 1922. The patient whose case forms the basis of this paper was. ill for many months with symptoms of encephalitis. The spinal fluid showed numerous yeast-like organisms which proved to belong to the torula group. A chronic meningitis was found at the autopsy with lesions in the optic thalami and an abscess at the base of the right lung.

The case occurred in a nurse, aged 40 years, who complained of very severe generalized headaches which had been constant and which were increasing in severity; symptoms had been complained 
of in the summer of 1922, and at the same time there had been a discharge from one of the ears, but after a holiday matters had improved somewhat, and it was not until about six weeks before she came under her doctor's care in December, 1922, that the headaches, which had been intermittent at the first, became constant. Vomiting was also present at this time, but no other subjective neurological symptoms. There had been no rise of temperature at any time. Bettin found a very stiff neck, painful on attempts at flexion and rotation; Kernig's sign was present, the deep and superficial reflexes were slightly increased, the pupils mid-wide and active to light and convergence. There was no clonus or Babinski, no history of sphincter trouble and no cranial nerve involvement, the fundus was normal, the retinal veins showing, perhaps, an unusual fullness. Lumbar puncture gave a clear fluid under considerable pressure; no acid-fast organisms were present and the Wassermann reaction was negative.

The patient grew worse, the headaches became more intense, vomiting was of frequent occurrence and the temperature ranged between $98^{\circ}$ and $102^{\circ} \mathrm{F}$. After a few days there was a remission, but a relapse soon followed and, shortly after this relapse the patient complained of cloudy vision and a moderate neuro-retinitis was noted; blindness quickly supervened, without any marked change in the fundus picture being observed. Attempts at lumbar puncture failed on account of the extreme spasm of the lumbar muscles and the hyperextension of the spine, but as the patient became more stuporose complete relaxation with loss of reflexes made it possible for a puncture to be done, and the fluid drawn off was found to be opaque, whitish in colour, with evidence of suspension in it of some foreign substance which proved to be yeast.

A full account is given of the laboratory findings and the postmortem findings, with pictures of a section of the brain showing the torula organisms, also the spinal fluid showing the same, and a culture slide. The author places the initial lesion probably in the lung; the case was discussed by. Pierson and Evans.

$$
\text { R.R.j. }
$$

(3) Klainguti, R.-Colour sense disturbance in retinitis pigmentosa and total colour blindness. (Farbensinnesstörungen bei Retinitis pigmentosa und totale Farbenblindheit.) Univ.Augenklin., Zürich. abs. Zentralbl. $f$. d. gesamte Ophthal., March, 1924.

(3) Klainguti records a family where four of the children suffered from retinitis pigmentosa and a colour sense disturbance 
amounting to what seemed a total colour blindness. The greatgrandmothers of the family were sisters. Examination was made of the mother and one of her sisters as well as of the four affected children. So far as could be ascertained the remaining children and the father were normal. The four children are minutely described. Coarse and fine nystagmus was present, and the visual acuity was $3 / 60-6 / 24$. Optic discs were grey and the periphery of the fundus was marble grey. Pigment spots were present round the vessels, and in one case there were white spots. Field of vision was contracted down $20^{\circ}-30^{\circ}$, up to $50^{\circ}$. Dark adaptation was reduced. In two cases the Wassermann reaction was negative.

Colour Tests. None were recognized (Stilling) except the first two red-greens, and the simulation tests. In the spectrum, the red and violet ends were shortened, with the most luminous area in the yellow, next in the orange-red and next in the light green. In the wool tests those dyed deeply were placed together fairly correctly but with hesitation. Otherwise there was more or less striking confusion between red and yellow, green and blue. In single colours of a highly different degree these were partly placed together correctly. The colour sense disturbance differs from that of the totally colour blind in the inability of the latter to recognize even the deeply dyed samples. With regard to the difference in the naming of the most luminous part of the spectrum (in the total colour-blind this is at $520 \mu \mu$ ), the total colour-blind hesitated to name the colours, while the retinitis pigmentosa cases did, even when they made mistakes. In the latter also the typical photophobia was absent, and the nystagmus was coarser, except in the youngest. Hence it is thought that there is a disturbance of colour sense produced by the retinitis pigmentosa. It is suggested that this would be more frequently found if more exact examinations were made. The suggestion of the coupling together of retinitis pigmentosa and total colour-blindness is set aside, especially on account of the difference of the ascertained colour disturbance from that of the typical monochromasia.

\section{S. Spence Meighan.}

\section{(4) Cottle, Maurice $\mathrm{H}$. (Chicago).-Post-operative adhesions of} the vitreous to the cornea. Amer. Jl. of Ophthal., April, 1924.

(4) Cottle having noted that references to this condition are very rare, proceeded to make a series of slit-lamp examinations of cases where an intraocular operation had been performed. He gives details of four such cases. In the first, after a discission for secondary cataract, threads of vitreous could be seen coming through the hole in the capsule to be attached to the corneal wound. Cauterization of the latter brought about healing and disappearance of the threads. 
In the second, a spontaneous haemorrhage had occurred into the anterior chamber after various operative procedures, and the haemorrhage was seen to occupy the upper part of the chamber; slit-lamp examination revealed a prolapse of vitreous, with blood on its upper surface.

In the third, following discission, the pupil was found to be horizontally oval, owing to the traction exerted by two bands of vitreous coming forward through the pupil to the two needle wounds in the cornea.

In the fourth, irregularity of the pupil following cataract extraction and iridotomy was found to be due to vitreous adhesions.

These adhesions vary in structure, some being fine threads, others large tough yellowish fibres. They have no tendency to disappear spontaneously, and in one case had been present for nineteen years. Where there is a fluid vitreous, formation of adhesions is impossible, and with a normal vitreous they are found only when the site of the corneal wound is an appreciable distance centrally from the limbus.

\section{F. A. Williamson-Noble.}

\section{(5) Majewski, K. W. (Cracow).-On a case of spastic pseudo- myopia. (Sur un cas de pseudomyopie spastique.) Rev. Gén. d'Ophtal., October, 1923.}

(5) Majewski relates a really extraordinary case of persistent, constant (in the sense of unvarying) pseudomyopia of seven dioptres in a practically emmetropic male patient whom he has kept under observation for the long period of twenty years or so; in fact, from the patient's age of twenty-five years till the onset of presbyopia and relaxation of the ciliary spasm at the age of forty-five years. The patient's history pointed to early commencement of the myopia, though the first glasses were not prescribed until his sixteenth year. Majewski has apparently waited all this time before publishing in order to see what would happen after the lapse of years, when, in the nature of things, the ciliary muscle would be obliged to give up the contest. Repeated atropinization. in this case always yielded the same result, namely, some half dioptre of hypermetropic astigmatism with the rule. An attempt was made at first to overcome the spasm by prolonged use of the cycloplegic and the wearing of plus glasses to enable the patient to carry on his work. As the patient presented absolutely no symptoms other than inability to see at a distance and as the atropin was, of course, a source of much inconvenience to him, this attempt had to be abandoned and the patient allowed to continue on his way. During the twenty years repeated examinations were made under cycloplegics and these invariably gave the same result, and invariably the spasm returned to exactly the same 
amount as before. At the age of forty-five years the patient was found to have given up the use of glasses and to have a visual acuity unaided of $6 / 8$ binocularly. The visual acuity of the right eye was 6/18 and with -1.5 D.sph., 6/6. That of the left eye was $6 / 12$ and with -0.50 D.sph., $6 / 6$. When homatropin was instilled the result came out exactly as it had done twenty years previously. The author has not been able to find in the literature any precisely similar case. His subsequent remarks are mainly concerned, as one would anticipate, with the bearing of this case (in which the eyes had been quite undamaged after twenty years of ciliary spasm) on the near. vision theory of the causation of myopia. The reviewer would remark, however, that this is only one case, and although Majewski suggests that numerous similar cases may be missed by ophthalmic surgeons through not using a cycloplegic he is unable to consider that this is probable. The attention drawn to the matter may perhaps bring similar cases to the memory of other observers.

\section{ERNEST THOMSON.}

(6) Krekler, Ferdinand (Würzburg).-. The structure of the sclera at different periods of life. (Die Struktur der Sklera in den verschiedenen Lebensaltern) Arch.f. Augenheilk., Vol. XCIII, September, 1923.

(6) The comparatively scant attention that the histology of the sclera has received and the conflicting findings of previous observers led Krekler to the investigation in question. The material for the research was obtained mainly from the cadaver, and to a small extent from operations. In most cases only the posterior segment of the globe was available. After fixation with formol the segments were sectioned on the freezing microtome, $20 \mu$ being the constant thickness of the section. As far as possible the cutting was done through the macular region and the optic nerve entrance. Great care was taken to obtain the flat sections which are indispensable for the proper study of the sclera. No embedding was done as both celloidin and, to a less extent, paraffin are unfavourable to proper tinting of elastic fibres. Weigert's resorcin-fuchsin mixture was the stain exclusively employed. The sections were stained from 3-5 minutes, and well washed in alcohol; a few drops of concentrated solution of picric acid added to the alcohol differentiated the connective tissue which it coloured distinctly yellow. Some were coloured with haematoxylin, and sclerae of advanced age were stained in particular with scharlach red for fat.

Of the 56 eyes examined, 35 came from cadavers of individuals over 60 years of age. For comparison the material is grouped into 
scleral tissue of (1) the young up to the 20th year ; (2) middle age from 20th to 60th year; (3) old age from 60 upwards. Of young eyes examined several were from the new-born. The development of the sclera appears incomplete at this stage of life, the paucity of elastic fibres in particular, which occur mainly in the posterior segment of the globe, is noticeable. Already in the first months of infancy the histological picture seems to change rapidly, the marked increase in elastic fibres uniformly distributed among all the layers of the sclera becomes obvious at a glance. The sclerae best suited for a satisfactory study of the course of the fibres are of young eyes until the end of the second decade of life. In this period the elastic fibres are not yet prominent in the scleral ring; the scleral tissue proper is yielding and translucent; it is relatively rich in cells which are large owing to their being not yet compressed and flattened; its fibrillary structure is not yet obvious; that the tissue is loose is shown by the marked wavy course of the bundles; the elastic fibres have hardly any tendency to undulation and pass straight over the waves of connective tissue.

In middle age the surprisingly large number of elastic fibres in the sclera is found unequally distributed among the lamellae. The amount of elastic fibres in the episclera remains about the same, in the sclera proper slightly diminished, more obviously in the anteriorthan in the posterior segment of the globe. The richness in elastic fibres of the innermost layers of the sclera is striking; it appears as? though the connective tissue fibres were spun round with a dense felt-work of elastic fibres. At the margin of and in the lamina cribrosa the wavy coarse elastic fibres so beset the picture as to constitute its salient feature as contrasted with the lamina cribrosa of the young eye. The equatorial region is comparatively poor and the posterior pole very rich in elastic fibres. The sclera itself is denser. The cells are flattened into spindles. The fibrillae are more evident. Under the age of 50, the reactions to stains and reagents for fat and calcium were invariably negative.

In the sclerae of individuals over 60 , Krekler paid particular attention to the quantitative estimation of elastic fibres. He came to the conclusion that in old age neither increase nor decrease in them could be made out. Individual fibres show no obvious regressive changes beyond an increase of volume here and there. The equatorial region shows even greater poverty in elastic fibres than in middle age. The posterior segment of the globe, particularly the posterior pole and the neighbourhood of the optic disc shows no variation of distribution of elastic fibres. On the other hand, the connective tissue fibre of the sclera in old age becomes considerably changed. The increase of density noticed in middle age becomes more pronounced and there is a further diminution of connective tissue cells. The most striking changes consist in deposits of fat and 
chalk between the connective tissue fibrillae. The initial seat of predilection for the deposits is the equatorial region; later the whole sclera becomes involved, sometimes appearing as though it had undergone fatty change in its entirety; invariably the inner lamellae are predominantly affected, the outer remaining comparatively free. Often even the lamina elastica of the choroid is strongly tinted by Sudan red. The calcic deposit is mostly in the form of phosphate.

The findings of this histological research are helpful in explaining the mechanical function of the sclera. The call for firmness, extensibility and elasticity in the sclera is answered by the intimate mixture of the tough connective tissue fibres with the elastic fibres. Contrary to the view of some authors even the connective tissue fibres are extensile in certain measure. The regressive changes, particularly deposition of fat and chalk, in the connective tissue in advanced years and consequent increased rigidity of the sclera in spite of the elastic fibres remaining undiminished and unchanged, are, in the opinion of Krekler, of significance in certain diseases of the eye, particularly glaucoma.

D. V. GIRI.

(7) de Lapersonne, S. (Paris). - Orbital tumour of mixed characters. (Iumeur mixte de l'Orbite.) Arch. d'Ophtal., August, 1923.

(7) The patient, a female, aged 41 years, had had signs of orbital tumour for seven years, and when she came under observation in October, 1922, exhibited a very large growth in the right orbit, projecting more than $3 \mathrm{~cm}$. Radiography showed that the orbit was completely filled by an osseous mass of pyramidal shape, covered anteriorly by a soft lobulated growth. The anterior, soft, portion of the tumour with the eyeball and stretched optic nerve was removed en masse, and the osteoma was subsequently extirpated without much difficulty.

Seven months later the condition of the patient and of the orbit was satisfactory.

The histological characters of : the tumour were very varied. The bony portion which corresponded exactly to the shape and dimensions of the orbit, was composed of compact dense osseous tissue. In front of this was another growth "the size of a small nut" and ensheathed in cellular tissue; its consistence was less than that of the larger osteoma. The structure of the soft (extraorbital) portion of the tumour varied greatly in different parts. Anteriorly the cells were large and fusiform, with long nuclei, staining deeply; they terminated in thin wavy fibrils, passing in all directions. In an adjoining portion the cellular elements were more closely set and gave an appearance of a fibroma, the cells 
being long, fusiform and tapering, with one nucleus and sometimes two. The cells were arranged in close irregular columns, and an appearance of vortices was noticeable in the sections. In still a third zone were found all the characters of a fusiform-celled sarcoma, with newly formed blood vessels, in a finely fibrillated matrix. There were also, in this part, some giant myeloplaques and fine strands of unstriped muscle fibres. Striated muscle-fibres, evident in the peripheral parts, were derived from the ocular muscles.

J. B. LAWFORD.

(8) Blatt, Nicolas (Roumania).-Clinical and pathological study of primary anthrax of the eyelids. (Klinik und Pathologie des primären Lidanthrax.) Arch. f. Ophthal., Vol. CXI, Leaflet 112, 1923.

(8) Blatt had the opportunity of observing ten patients in 1922 during an anthrax epidemic, of whom three presented a primary infection on the right upper lid. These three patients further presented very serious general symptoms. The infections of the eyelid presented peculiarities with regard to form and evolution. Whereas the other cases presented the typical characters of the malignant pustule, in the case of the eyelids there developed a diffuse oedematous inflammation, because the loose skin and subcutaneous. tissue offered insufficient opposition to the process of invasion? As a general rule four stages could be differentiated in the evolution of the disease. In the first stage one notes redness of the eyelid, with itching and a burning sensation, but without actual pain. The eyelid continues to swell. While general symptoms of alarming gravity develop, the pre-auricular and sub-maxillary lymphatic glands increase in size, and the oedema extends towards the temporal region and downwards over the face. The skin develops a livid hue. The second stage is characterized by the formation of necrosis in the superficial and deeper tissues of the eyelid, which takes the form of a dark-brown to deep-black slough. During the third stage the general symptoms begin to abate, while a purulent line of demarcation limits the sloughs: The slough is cast off, and there remains a deep loss of substance, with undermined and swollen edges. In the fourth stage the ulcer becomes cleaner, and finally closes by a process of cicatrization, or advances as the result of a moist gangrene which may extend to the bulb. The development of the pustule at the same place, that is the right upper lid, in the case of all three patients, is to be explained by the fact that they had all been occupied in skinning animals that had died from anthrax, and had been stung by the flies that swarmed about them. The infectious material originated in the blood of the dead animals, which in the first case spurted on to the patient's eye, and in the 
perspiration on their brows and eyelids. As the patients applied early for medical help it was possible to determine accurately the period of incubation, which was four days in the two first cases and five days in the third. In spite of the deep anatomical changes the functional results were fairly satisfactory. The eyelids retained their normal position and their movements were but little diminished. The absence of ectropion was accounted for by the fact that the scarring extended deeply into the subconjunctival tissue at the line of reflection and even to the periosteum. One case developed panophthalmitis. The general treatment is purely symptomatic. The author tried intravenous injections of neosalvarsan, and is convinced of the efficacy of this treatment, so far as the general state is concerned. The local manifestations do not seem to be affected by neosalvarsan. The local treatment must be entirely conservative, moist compresses and fomentations with weak mercurial lotions.

V. ST. JоHN.

(9) van Duyse, D. (Ghent), and Moret (Charleroi).-Pseudoosteoma of the orbit (fibro-myo-lipo-épithelioma with calcification) and epithelial-osteoma of the temporal fossa, contiguous to the great wing of the sphenoid. (Pseudoostéome de l'orbit [fibro-myo-lipo-épithéliome calcifié] et epithélio-ostéome de la fosse temporale, attenant au niveau de la grande aile du sphénoïde.) Arch. d'Ophtal., March, 1924.

(9) van Duyse and Moret report their case in detail and the histological findings are illustrated by several microphotographs. Apart from the interest of the case in relation to the development and nature of the neoplasm, a notable feature was the calcification of the orbital growth. This had occurred so extensively that an X-ray examination seemed to render a diagnosis of a bony growth in the orbit almost a certainty. The patient was a female, aged 32 years, in whom the first symptom (proptosis) was noticed only three months before she came under observation.

When seen by van Duyse the exophthalmos was well marked, but there was an entire absence of congestion, paralysis of nerves, papilloedema, pulsation or bruit.

The growths were removed from the temporal side after resection of the zygomatic arch. In spite of the severity of the operation, necessitating exposure of the intracranial cavity close to the outer margin of the cavernous sinus and resection of the wing of the sphenoid, the recovery was uninterrupted and rapid, the patient leaving the hospital at the end of a fortnight.

The new growth in the orbit had very varied histological characters, and the authors call it fibro-myo-lipo-epithelioma. It was rich in fibrillated tissue, and in parts showed muscular and fatty 
tissue, and spaces filled by epitheliomatous cells. The tumour of the temporal fossa, which was contiguous to the orbital growth, consisted largely of osseous tissue, in which were irregular cavities; these were surrounded by concentric bony lamellae; in places a line of osteoblasts extended the length of the lamella to the alveolus. At the periphery of these alveoli was a tissue composed of long loose fibres enclosing connective tissue elements and capillaries. The central part of the alveoli was occupied by a collection of flat epithelial cells, resembling the epithelial elements of the orbital tumour, but being less sharply edged.

An interesting discussion as to the pathogenesis of this unusual tumour follows the description of its clinical and histological characters.

J. B. LAWFORD.

\section{IV.-INSTRUMENT}

(1) Cambridge Scientific Instrument Co.-The Cambridge Ophthalmoscope.

(1) This ophthalmoscope is similar to that designed by the late Professor Wertheim Salomonson.* Various modifications have been made in the design, but the optical system is essentially the same. By means of the apparatus it is possible to obtain photographs of the fundus about $44 \mathrm{~mm}$. in diameter, covering a very large proportion of the total fundus and enabling both the disc and yellow spot to be shown on one plate; the plates produced are capable of considerable enlargement.

The ophthalmoscope consists of two optical systems, one being used for illuminating and the other for viewing and photographing the fundus. A beam of light from a small arc lamp passes through a condenser and a lens and forms an image of the condenser in the plane of an aplanatic-aspheric lens; this illuminating beam is in turn reflected into the eye. The fundus is viewed by means of an eye-piece; to photograph the retina, this eye-piece is conveniently and quickly replaced by a photographic plate. Before photographing it is necessary to focus the image; this can only be done if the intensity of light has been much reduced, as the of patient would not be able to suffer the prolonged action of so $\tilde{N}$ strong a light. To overcome this difficulty, the instantaneous shutter, with which the instrument is fitted, is placed in front 0 of the prism in the illuminating tube. When in the position of

*Transactions of the Optical Society, Vol. XXII, p. 53, 1920-1921. 
being set, the shutter presents an opening covered with aluminium foil perforated with a number of tiny holes, through which enough light passes to enable the operator to examine carefully the fundus and focus the image, at the same time causing the patient no discomfort. The exposure of the full beam of light may be varied from $1 / 20$ to $1 / 5$ of a second; in practice it will be found that an

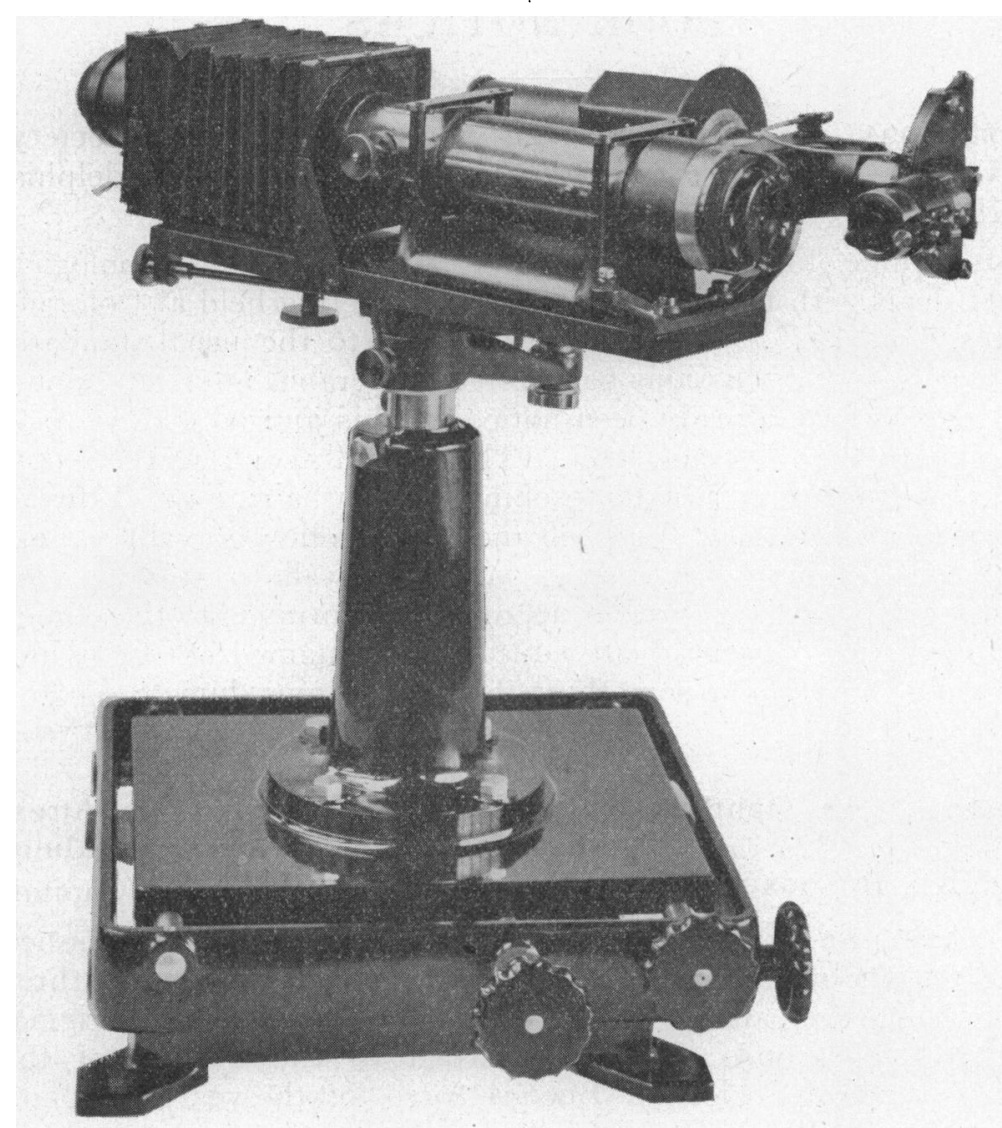

exposure of $1 / 10$ of a second will generally suffice. Owing to the careful design of the optical system, all secondary reflections from the ophthalmoscope lens and cornea are eliminated. Provision is made whereby the ordinary lenses used for astigmatism can be placed in a standard clip in front of the ophthalmoscope lens. The whole instrument is mounted on a bench, and is capable of adjustment in three directions in order that it can be carefully adjusted into close proximity to the eye under observation. A 
novel arrangement enables the whole instrument to be swung through an angle of 180 degrees without removing it from the base, thus rendering it possible to obtain photographs of the retina of either the left or the right eye easily and quickly.

\section{BOOK NOTICES}

Transactions of the American Ophthalmological Society. Vol. XXI, 1923. 327 pp. 25 plates, 3 coloured. Philadelphia, 1923.

This volume of the transactions of the American Ophthalmological Society deals with the fifty-ninth Annual Meeting held at Colorado Springs, Col., 1923. The matter is well up to the usual standard, both papers and discussions being of considerable interest. Some of the papers have already been noticed in this journal and we hope to publish further abstracts later. The appendix contains the report of a committee on graduate teaching of ophthalmology (Edward Jackson, chairman, F. H. Verhoeff and T. B. Holloway), which those engaged in teaching the subject would do well to study. One sentence might well be written up over the entrance to the clinic: "The perfection of a graduate education is attained not by telling or showing the student something, but by training him to see and do it himself."

Reports of the Ophthalmological Hospital of Buenos Aires. Vol. VI, 1923. (Communicaciones del Hospital Oftalmologico, Buenos Aires). Sociedad de Beneficencia de la Capital.

This brochure of 107 pages is the sixth volume of reports issued by the Ophthalmic Hospital of Buenos Aires. It consists of three sections. The first, and by far the largest, is occupied by the original papers; the second gives an abstract of the session of the Ophthalmological Society of Buenos Aires for the year 1923, and the last consists of reviews of subjects of ophthalmological interest from the Argentine medical papers. There is also an account of the opening of the new Ophthalmic Hospital of Santa Lucia. The original papers number only seven; Soriano has a long communication on colour vision and its anomalies. Marque and Oyenard, a short account of a case of amaurotic family idiocy in the family of a Russian Jew and Jewess, with a good coloured plate. Oyenard deals with the frequency of granular lids in Buenos Aires. Echavarria writes on the ocular complications of sinusitis. Androgue has three papers: one on tobacco-alcohol amblyopia, and the other 